Marcela Pezzuto*

Universidad Católica de Argentina (Argentina)

marcelapezzuto@gmail.com

\title{
Una aproximación al discurso «Conquista Espiritual» de Antonio Ruiz de Montoya a través del estudio de las imágenes benévolas
}

\section{An approach to Antonio Ruiz de Montoya's "Conquista Espiritual» discourse through the study of benevolent images}

Resumen: En el relato de la fundación de pueblos, de la evangelización y de la defensa de las comunidades de la región del Guayrá, del Paraná, del Uruguay y del Tape se menciona como habitual la convivencia de la geografía humana y natural con seres sobrenaturales. Las misiones jesuíticas, espacios delimitados y diferenciados del «exterior», se muestran para el padre Montoya como el sitio propicio para la interacción del hombre con la divinidad. Allí las presencias celestiales guiarán a los indios a llevar una vida apegada al precepto y a la doctrina y se constituirán en ayudantes de los religiosos. Dichas figuras de «rescate» (entre las que se destaca especialmente la del Apóstol Santo Tomás) aparecen en el relato como instrumento para liberar a los indios del mal, conformando, así, un mensaje esperanzador. Nuestra propuesta se centra en una doble metodología que contempla un estudio lingüístico-estructuralista $y$, posteriormente, una lectura hermenéutica. El objetivo es revelar en la narración del jesuita la estructura, los actantes, las tensiones nodales y las redes isotópicas para luego reflexionar sobre el contenido semántico del mensaje que manifiesta el estado de cosas propias del universo simbólico de Ruiz de Montoya.

Palabras clave: Montoya, ayudantes, esperanza, Santo Tomás.

\begin{abstract}
: the natural human geography, living together with supernatural creatures, is often narrated as ordinary in the chronicles of towns foundations, evangelization and the defense of the communities from Guayrá, Paraná, Uruguay, and Tape. The Jesuitic missions, strongly separated and delimited from the outside, appear to be, for father Montoya, as the very specific space for interaction between men and God. The heavenly figures will guide Indians to live according to the dogma and will be the priests' helpers. These figures of «rescue» (among which stands out especially St. Thomas the Apostle) appear in the story as an instrument to liberate the Indians from Evil, forming thus a hopeful message. Our goal is to offer a linguistic and structural approach, together with an hermeneutic reading. The aim is also to reveal the narrative structure of the Jesuit, the actants, the nodal tensions and the isotopies networks, in order to think on the semantic content of the message that shows the state of the art in the very symbolic universe of Ruiz de Montoya.
\end{abstract}

Keywords: Montoya, assistants, hope, Saint Thomas.

* Doctora en Letras con sede de trabajo en la Pontificia Universidad Católica Argentina. Es especialista en Literatura colonial latinoamericana y sus más recientes publicaciones son: Conquista Espiritual de Antonio Ruiz de Montoya: el texto y sus voces. En: Revista Lexis, vol. 41 № 1, 2017. Pontificia Universidad Católica del Perú, y Desde el Titicaca hasta el Guayrá: el gran viaje de Santo Tomás según dos cronistas. En: Revista Cuadernos de Historia. $\mathrm{N}^{\circ}$ 44, 2016. Universidad Nacional de Chile. 
Dentro de los estudios coloniales a los que nos dedicamos la figura del padre Antonio Ruiz de Montoya nos convoca especialmente por la importancia de sus escritos y la destacada actuación en la zona de las misiones jesuíticas del Virreinato del Río de la Plata tanto desde el aspecto religioso, como desde el social y el político. En esta ocasión nuestro objetivo consiste en analizar y comprender la funcionalidad que tienen las reiteradas descripciones de presencias benéficas en su discurso como sujetos actantes que, a lo largo de Conquista Espiritual del Paraguay ${ }^{1}$ (1639) marcan el vínculo entre jesuitas y los pueblos indígenas.

La importancia que alcanzó la Compañía de Jesús con la política reduccional en la zona del noroeste argentino, sudeste paraguayo, sudoeste brasileño, y noroeste uruguayo es sabida y reconocida. Numerosos estudios resaltan la labor evangelizadora, instructiva y humanitaria que caracterizó el accionar de los religiosos. Los especialistas han abordado el modo de conducirse de la Orden a partir de variadas lecturas entre las que se destacan la histórica, antropológica, sociológica y religiosa. Nuestro aporte pretende centrarse en la conformación discursiva de Conquista Espiritual considerada como una estrategia dirigida a alcanzar dos objetivos: salvar las almas de los indios y ofrecer los medios para lograr su desarrollo dentro de un espacio marcado por el orden.

La línea de trabajo que seguimos contempla un estudio lingüísticoestructuralista tendiente a desarmar las cadenas de palabras que conforman el texto de Montoya con el fin de revelar la estructura de su discurso en sus actantes, en las tensiones nodales y en las redes isotópicas. Es decir, analizaremos la obra como acto locutivo. Sin embargo, como nos interesa develar y reflexionar sobre la semántica de las palabras, apelaremos en un segundo momento a una lectura hermenéutica que interprete el elemento simbólico de aquellas a fin de revelar su imagen originaria y generadora. De esta forma concluiremos cada sección del presente estudio con una doble lectura del texto: una primera que congregará los estudios de las ciencias del lenguaje $\mathrm{e}^{2}$ y otra posterior, hermenéutica, con la que pretendemos comprender el mundo de la cultura ${ }^{3}$ de Ruiz de Montoya. Por ello proponemos un estudio de la obra Conquista Espiritual alejado de la mera literalidad que, en definitiva,

1 Antonio Ruiz de Montoya: Conquista Espiritual hecha por los religiosos de la Compañia de Jesús en las Provincias de Paraguay, Paraná, Uruguay y Tape [1639]. Equipo Difusor de Estudios de Historia Iberoamericana, Rosario, 1989. Para este trabajo seguiremos las lecturas de Greimas, Foucault, Lévi-Strauss, Ducrot y van Dijk.

Cfr. Paul Ricoeur: Hermenéutica y Estructuralismo. Traducción de Graziella Barravalle y María Teresa La Valle, Megápolis, Buenos Aires, 1975. 
revelaría una lectura simple, es decir, la incomprensión de la insistencia con que el jesuita aborda la presencia de figuras celestiales y también del demonio en el espacio misional. Nos impulsa descubrir el imaginario cultural ${ }^{4}$ subyacente que, a través de un proceso de selección de secuencias oracionales, demuestra las relaciones lógicas que Antonio Ruiz de Montoya realizó para explicar la presencia del Bien. En otras palabras, nos dedicaremos a encontrar un orden lingüístico centrado en las relaciones intrasignificantes para luego, a través de la recuperación de los elementos simbólicos, interpretar su realidad extralingüística.

La importancia histórica que alcanzó nuestro autor nos obliga a demorarnos en un esbozo biográfico que contextualice su obra. En 1585 en Lima, Perú nació el padre Montoya, hijo de un español acaudalado y de una dama peruana. Prontamente quedó huérfano al cuidado de tutores que se encargaron de que la voluntad de su padre fuera cumplida: estudiar en el colegio San Martín dirigido por padres jesuitas. Luego de un período en el que malgastó el legado paterno, optó por seguir la vida religiosa en la Compañía de Jesús ingresando en 1606 con 21 años. Poco después viajó a la ciudad de Córdoba para concluir sus estudios de teología y filosofía. Durante su noviciado fue destinado a la Provincia del Paraguay recientemente creada y fundada por el Padre General Claudio Acquaviva. Los superiores al ver su marcada vocación misionera lo enviaron a establecer nuevas poblaciones con indígenas guaraníes en regiones de los actuales territorios de Paraguay, Brasil, Argentina y Uruguay. Entre 1611 y 1612 Ruiz de Montoya junto con una decena de jesuitas comenzaron la fundación de las célebres reducciones de las cuales llegará a ser Superior.

En 1628 y frente a la amenaza de los esclavistas portugueses de San Pablo, emprendió el éxodo de todas las poblaciones de la región del Guayrá -territorio actual del sur de Brasil- hasta la actual provincia de Misiones. Esta proeza involucró a más de doce mil guaraníes que recorrieron cerca de mil kilómetros. El resultado de este viaje fue nefasto ya que pereció la mayoría de los indios y sólo delante de esta catástrofe las autoridades coloniales comenzaron a reaccionar. Así, Montoya peticionó ante la administración virreinal que los indígenas pudiesen defenderse y con este motivo fue enviado a Madrid para realizar gestiones más efectivas en la propia corte española. Finalmente, en 1637 (luego de veinticinco años de trabajo entre los guaraníes) viajó a 
Buenos Aires junto con el P. Díaz Taño para embarcarse con dirección a Europa (donde permaneció hasta 1643) para cumplir una nueva misión: la de Procurador.

En esta nueva etapa en las cortes concluyó una importante producción de libros en los cuales utilizó la palabra de manera política con la finalidad de construir un discurso que señalara los méritos obtenidos en las reducciones y lo que aún restaba por alcanzar. Como escritor polifacético, Montoya manifestó una gran habilidad al emplear variedades discursivas como la lingüística comparativa, la oratoria -con fines evangelizadores-, y la crónica -género muy utilizado en los relatos del descubrimiento y de la colonia-. En el caso particular de Conquista Espiritual su finalidad principal fue narrar la acción evangelizadora: alejando a los indios de la rusticidad y convirtiéndolos en cristianos con derechos (como miembros de un reino). Por ello el relato describe la conversión espiritual y la consecuente construcción política al pretender transformarlos en actores de una comunidad. Para la concreción de estos objetivos Montoya menciona tres temas que inciden directamente en la empresa jesuita: 1) la ausencia de creencias religiosas de los indios, ${ }^{5}$ 2) la presencia del demonio ${ }^{6}$ y 3 ) la presencia de figuras benefactoras.

Frente a los inconvenientes con los que se topaba la empresa religiosa, Montoya consigue presentarle a Felipe IV alegatos, memoriales e informes con la finalidad de demostrar el grave estado de desprotección que enfrentaban las misiones ante el avance de los bandeirantes. Sin embargo, en diciembre de 1640 con motivo del levantamiento por la Restauración de la Independencia del reino de Portugal se frustraron, en gran medida, todas las actividades hasta entonces realizadas. Recordemos que Montoya llegó a concretar una entrevista con el monarca español en la cual éste se interesó por la situación colonial y hasta llegó a encargar su resolución al Consejo de Indias que, a su vez, propuso un conjunto de medidas para contener la invasión paulista. Sin embargo, este final abrupto del trabajo en España y su posterior regreso a Lima, no significaron que Ruiz de Montoya abandonara su actividad de abogado de las reducciones. En 1644 y 1646 reclamó ante el Virrey armas

\footnotetext{
Hemos trabajado este tema en el artículo inédito El narrador etnógrafo en «Conquista Espiritual» de Ruiz de Montoya. La mirada puesta en el otro. Dicho trabajo ha sido posible gracias al Programa de Perfeccionamiento docente y Transferencia otorgado por la Universidad Católica Argentina.

6 En el artículo inédito La simbología del mal en «Conquista Espiritual» hemos estudiado la presencia de diferentes figuras malignas que aparecen en la obra de Montoya. Dicho trabajo fue realizado gracias al aporte económico de la Universidad Católica Argentina mediante el programa de beca de Plan de becas de Perfeccionamiento académico e Investigación.
} 
de fuego para que los guaraníes pudieran defenderse ${ }^{7}$ y en 1647 le recordó también las disposiciones en que se eximía a los indios de los servicios personales, insistiendo en que fueran inscriptos como vasallos del rey y paguen tributo. Finalmente, Montoya falleció en la Ciudad de Los Reyes de Lima el 11 de abril de 1652.

Conquista Espiritual fue escrita y publicada en España en 1639 y constituye el corolario de la extensa tarea de los jesuitas en las misiones del Paraguay, Paraná, Uruguay y Tape. Como tantos otros textos coloniales posee una interesante diversidad discursiva entre las que podrían señalarse el relato etnográfico, el antropológico, la historia de una primera evangelización, ${ }^{8}$ las Cartas Anuas, la Cédula real y la biografía. Esta variedad de enunciados es concebible dentro de una obra construida por un sujeto que asume la vOz narradora unificando el discurso bajo la formalidad del alegato.

Antes de pasar al análisis de Conquista Espiritual mencionaremos -para guiar al lector- la división interna que la crítica ${ }^{9}$ ha observado en su temática. Los 81 capítulos que la componen han sido divididos en cuatro secciones:

- Primera parte: en la que abundan descripciones etnográficas y geográficas (capítulos I a III y X).

- Segunda parte: donde se relata la tarea evangelizadora entre los guaraníes (capítulos IV a IX; XI a XX y XXX a XXXIX) y la prédica del apóstol Santo Tomás en América (capítulos XXI a XXVI).

- Tercera parte: trata sobre la descripción de las reducciones y la biografía de cinco padres (Espinosa, González de Santa Cruz, Rodríguez, del Castillo y de Mendoza) (capítulos XLIV; XLV; LVI a LXX y LXXI a LXXII).

- Cuarta parte: narra los últimos ataques de los paulistas en el Tape (capítulos LXXIV a LXXVII).

\footnotetext{
Cfr. Edgardo Calvi: Las milicias de las doctrinas jesuíticas del Paraguay. Origen, evolución e influencia social y politica. En: JORNADAS. Aporte de las Universidades Católicas al Quinto Centenario del descubrimiento y de la evangelización de América. Su misión ante la nueva evangelización. Tomo II. Buenos Aires, septiembre, 1992, pp.113-123

8 En un trabajo anterior (dependiente del Programa de Estímulo a la Investigación de la Facultad de Filosofía y Letras de la Universidad Católica Argentina) hemos abordado la figura del Apóstol Tomás, figura de la que se ocupa particularmente Ruiz de Montoya. El relato de la tarea evangelizadora del santo en tierras americanas es presentada previa a la empresa conquistadora. Con lo cual la existencia de un protocristianismo en las religiones autóctonas era visto como facilitador para los indígenas a fin de acceder a la doctrina evangélica.

9 Antonio Ruiz de Montoya: Conquista Espiritual..., p. 23.
} 
Sin embargo, tal como dijimos unas líneas más arriba, debemos destacar que hacia el final del libro se presentan otros capítulos que se diferencian del conjunto discursivo que los antecede. Nos referimos a los capítulos LXXVIII a LXXXI que presentan el siguiente formato discursivo: un exhortatorio, dos cartas y una Cédula Real. (Capítulo LXXVIII - «Exhortatorio del Obispo de Tucumán al Provincial de la Compañía de Jesús, P. Diego Boroa»; Capítulo LXXXIX - «Carta del obispo de Tucumán al rey de España»; Capítulo LXXX - «Carta de D. Pedro Esteban Dávila, gobernador de Buenos Aires, al rey de España» e Capítulo LXXXI - «Cédula Real de 1633 enviada a Perú en defensa de los indios»). Estos documentos tienen la finalidad de otorgarle valor al desempeño de la Compañía de Jesús, en general, y a la actuación de Montoya, en particular.

\section{La presencia de ayudantes}

En el relato de la fundación de pueblos, de la evangelización y de la defensa de las comunidades misioneras se menciona como habitual la convivencia de la geografía humana y natural con seres sobrenaturales. Dentro de las reducciones jesuíticas el encuentro y contacto de religiosos y aborígenes con figuras del mundo espiritual es descrita como cotidiana. En esta oportunidad nos ocuparemos de las once figuras celestiales que se aparecen en veinticinco oportunidades con el único propósito de brindar socorro. Éstas son: Dios / Cristo / la Virgen María / San Ignacio / San Pedro / San Francisco Javier / Arcángel Miguel / Ángel de la Guarda / Padre Urtazum / almas del Purgatorio / alma de un indio cristiano.

Dichas imágenes, ayudantes en la tarea evangelizadora, se oponen a los constantes embates de magos, chamanes, caciques, bandeirantes y hasta del mismo demonio. Estas figuras aparecen en trece capítulos distribuidos entre la segunda, tercera y cuarta parte. ${ }^{10}$ Nuestro corpus, entonces, se concentrará en este recorte y será sobre dicha selección que aplicaremos el estudio lingüísticoestructural propio de las Ciencias del Lenguaje. Para lo cual estudiaremos especialmente cómo Montoya organiza las oraciones que arman su discurso.

${ }^{10}$ Segunda parte: capítulos XIV, XV, VII, XVIII, XIX, XXI; Tercera parte: capítulos XXXVIII, XL, XLVII, XLVIII, L, LIV, LXIV; Cuarta parte: capítulo LXXIV. Cfr. Antonio Ruiz De Montoya: Conquista Espiritual.... 
Partiremos de dos consideraciones: 1) entendemos la oración como más que una serie de palabras y 2) el texto es más que una secuencia, es decir, un conjunto de oraciones. En la búsqueda del sentido comprensible e interpretable de las oraciones tomaremos en primer lugar las proposiciones, es decir, el significado de las oraciones aisladas. En un segundo momento identificaremos las secuencias, es decir, las oraciones vinculadas por la condición de conexión y nos detendremos en la coherencia que mantienen. Por último, observaremos las unidades textuales mayores, no ya las oraciones aisladas y sus proposiciones, sino las conexiones que ensamblan un texto como un todo. Así, denominaremos macroestructura semántica al significado global del texto para llegar a desentramar la organización que guarda su información (van Dijk 1992: 37-58). Luego, a través de la semántica, buscaremos el significado de la obra de Montoya como acto de enunciación.

Consideraremos, entonces, el recorte mencionado de Conquista Espiritual (segunda, tercera y cuarta parte) como un discurso aseverativo que se concreta a partir del conocimiento, de la voluntad, de la creencia, de la intención, de la obligación y de la posición del escritor. Seguiremos, luego, con el concepto de la macroestructura y sus organizaciones jerárquicas. Así, en el nivel superior o global definimos la información como AYUDAS CELESTIALES que en niveles inferiores se desarrollará en microestructuras y en proposiciones. A partir de la unidad de sentido que hemos observado en la macroestructura y que se mantiene en todo el recorte podemos afirmar que dicha selección del relato constituye un texto unívoco dentro de la totalidad de la obra.

En Anexo (Cuadro I) hemos esquematizado las proposiciones (nivel inferior) que hemos aislado en veintisiete actos de habla y que evidencian el entramado de estructuras relacionadas que garantizan la conexión y la coherencia del texto para alcanzar su correcta comprensión. Estudiar las macroestructuras permite explicar por qué para el hablante intuitivamente ciertas series de oraciones son válidas como texto comprensible y aceptable, mientras que otras no lo son. Sin las macroestructuras sería imposible comprender el tema de un texto a pesar de que éste se exprese cabal o explícitamente. Así, para descubrir el tema de una obra el lector debe realizar una actividad de reconstrucción, es decir, de deducción que se apoya en macrorreglas aplicables a las series de proposiciones y que consisten en omitir, seleccionar, generalizar e integrar. Las dos primeras reglas consisten en la anulación, es decir, el lector u oyente descarta la información poco importante en relación al texto entero. Y las dos últimas son de sustitución por lo cual se sustituye una serie de conceptos por el 
sobreconcepto compartido que define el conjunto abarcador. ${ }^{11}$ En esta tarea de interpretar relaciones de significados generales, es decir, de deducir varios temas, el lector será capaz de realizar un resumen y también de encontrar palabras y oraciones temáticas que sinteticen el asunto del texto. La aplicación de las cuatro macrorreglas revela, además, una implicación semántica, por la cual la macroestructura debe estar contenida semánticamente por las proposiciones a las que se aplica la regla. ${ }^{12}$

En el Cuadro I hemos empleado específicamente las macrorreglas de selección y generalización para llegar a las proposiciones presentadas. Nos parece oportuno insistir en que con la regla de selección hemos reducido la información no esencial y con la de generalización hemos rescatado condiciones, circunstancias y componentes de la situación de forma que hemos podido formar un concepto más global del texto. ${ }^{13}$

También en el Anexo (Cuadro II) demostraremos cómo se completa el sentido del texto considerando quién realiza la acción, sobre quién recae y en qué momento sucede. Las oraciones (proposiciones) que hemos aislado en el nivel del significado se presentan siguiendo un criterio de verdadero o falso debido a que están relacionadas con el estado de las cosas que describen. Así, la oración resulta verdadera cuando remite a un estado de cosas que existe. ${ }^{14}$ $\mathrm{Al}$ aplicar estos conceptos a Conquista Espiritual hemos tenido en cuenta que quien asume el discurso es un religioso y que su circunstancia del mundo está traspasada por la fe, con lo cual resultan lógicas y esperables las presencias de entidades de tipo angelical, de almas puras y hasta del mismo Dios. En la esfera de la acción, del pensamiento y de la creencia de Antonio Ruiz de Montoya estas figuras pertenecen a su realidad inmediata puesto que forman parte de la propia circunstancia religiosa. Esto hace que la voz enunciadora presente como verdadera la descripción del mundo de Conquista Espiritual. La calidad de veracidad irrefutable se refuerza con el tipo discursivo elegido para producir los enunciados de gran parte de la obra: el informe. Mediante éste Montoya describe la historia de las fundaciones misionales siguiendo un ordenamiento temporal. Además, debemos decir que la referencia al realismo de la obra aparece anticipada ya en el paratexto (el título) ya que el valor del adjetivo Espiritual «ancla» el estado de cosas de las que se tratarán.

11 Cfr. Teun van Dıjk: La ciencia del texto. Traducción de Sibila Hunzinger, Paidós, Barcelona, 1992, p. 61.

12 Cfr. Teun van Dijk: La ciencia del texto..., p.58.

13 Cfr. Teun van Dıjk: La ciencia del texto..., pp.58-62.

14 Cfr. Teun van Dijk: La ciencia del texto..., p 39. 
A continuación presentamos el último esquema (Cuadro III) en el que se prioriza la jerarquía de la información dentro del entramado de significaciones.

\section{CUADRO III}

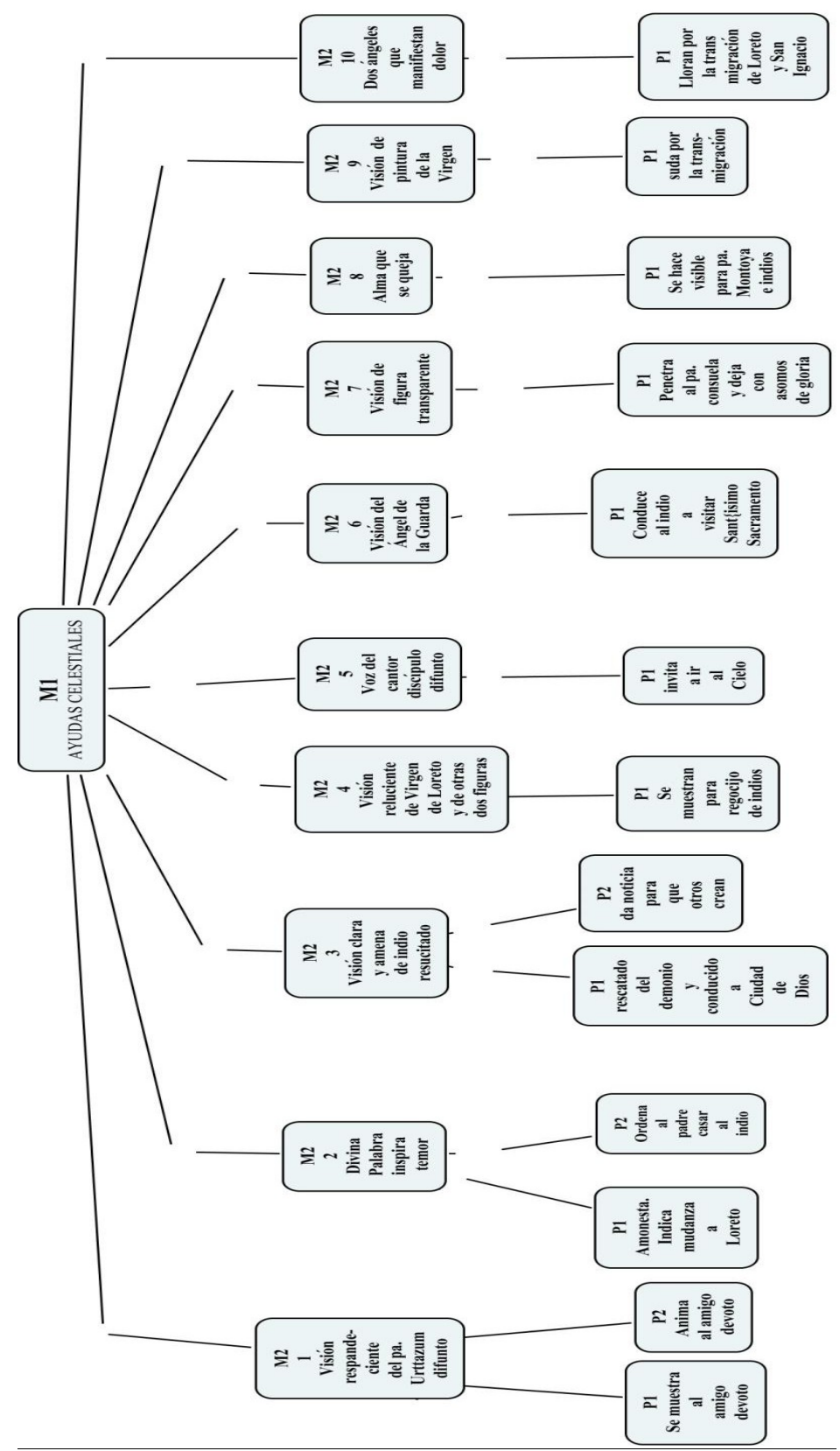




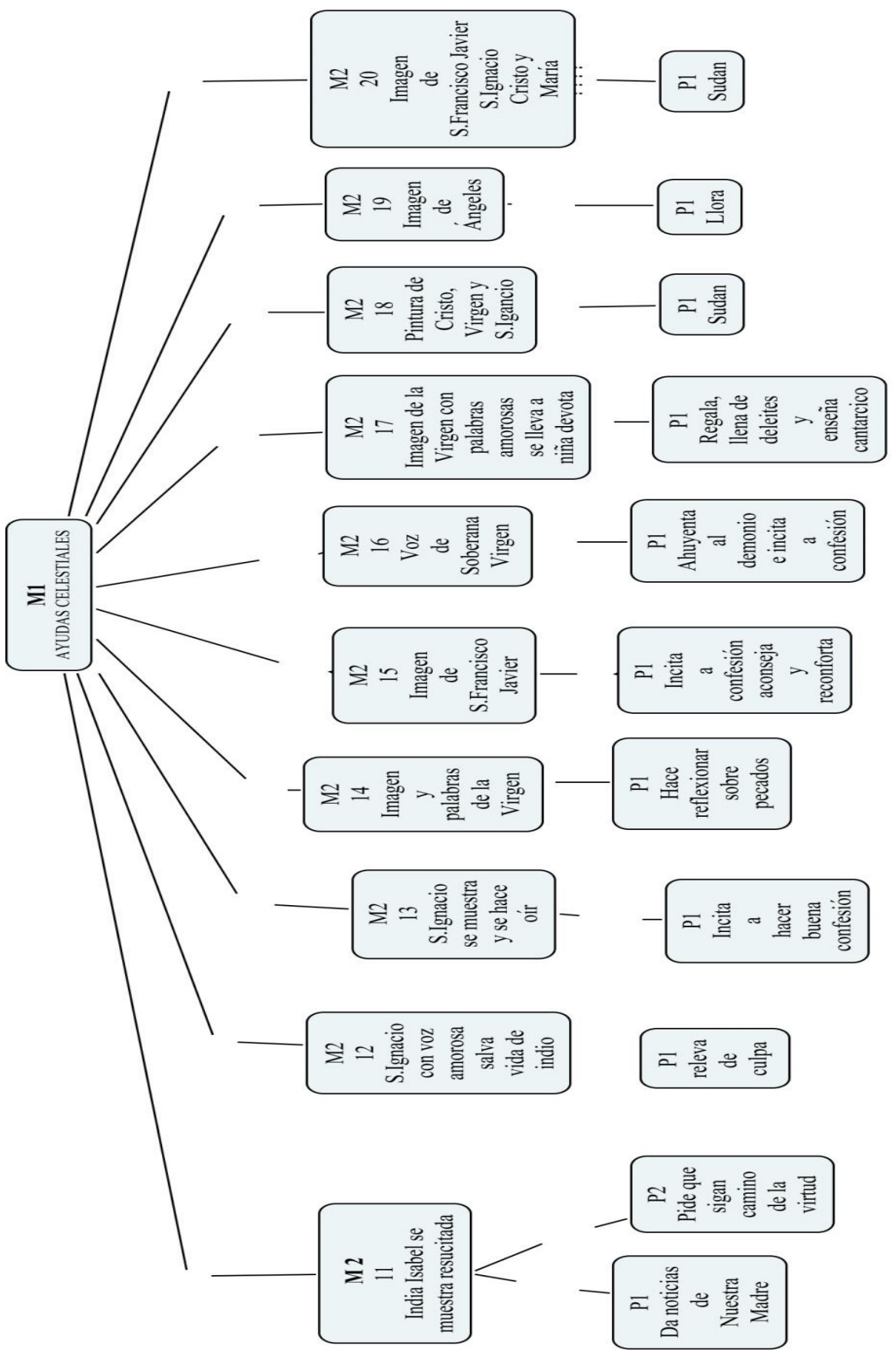


El tema o macroestructura (M1 en el Cuadro III) pone de manifiesto la intencionalidad de Montoya al presentar las figuras benévolas como auxilio de los hombres. Esta macroestructura constituye la representación abstracta de la estructura global de significado de todo el texto. En un nivel inferior, las palabras temáticas llamadas microestructuras (M2 en el Cuadro III) se centran en dos manifestaciones sensibles: visión y audición. Será a través de la vista que las realidades celestes se harán evidentes en la mayoría de los casos. Este sentido se presenta bajo dos modalidades: visión propiamente dicha (aparece en veinte oportunidades) caracterizada por la luminosidad: «resplandeciente», «reluciente», «clara» $\mathrm{y}$ «transparente» o por medio de la representación pictórica de Cristo, de María, de Ángeles y de San Ignacio. Bajo la forma de figuras retratadas en los cuadros que manifiestan claramente sentimiento de dolor a través del llanto o del sudor.

La segunda presencia celestial es la que se explicita a través de la expresión audible, dejándose oír en nueve ocasiones. Mayoritariamente se presenta como voz y posee varios matices: firmeza, inspirando temor (en el caso de la Palabra Divina), dulzura (como la empleada por la Virgen María o por San Ignacio) y como quejido que será escuchado sólo por el padre Montoya y que lo interpreta como la manifestación dolida de un alma del Purgatorio.

En el último nivel hemos aislado las oraciones que llamamos proposiciones (P1, P2, P3 en el Cuadro III) y que cargan con la información implícita o tópico. ${ }^{15}$ Será en este nivel que se producirá el socorro concreto por medio de acciones directas tendientes a aliviar la tarea evangélica, a ordenar la vida de los indios, a conducir a la vida virtuosa y a consolar a padres e indios frente a las durezas de las circunstancias. Así, podemos señalar que aplicando la macrorregla de generalización e integración, todas las proposiciones rondan la esfera del auxilio, sea que se manifiesten como reconfortar o bien como reprender. Así, el socorro constituye el tópico (elemento conocido) coherente que el lector va recogiendo a lo largo de la lectura de Conquista Espiritual y que condice con el tema y el tenor de la obra. Por otro lado, en todos los casos las figuras benefactoras tienen como fin asistir a los hombres en las reducciones de manera de conformar una red de acciones vinculadas por la construcción textual coherente de Montoya.

De los trece capítulos en los que aparecen las imágenes benefactoras, seis capítulos pertenecen a la segunda parte (evangelización de los guaraníes); otros 
seis están incluidos en la descripción de las reducciones y sólo un capítulo aparece en la cuarta parte que se detiene en el relato de los ataques paulistas. Las acciones realizadas por los ayudantes benéficos rondan las siguientes áreas:

- Alientan a una verdadera y profunda confesión.

- Animan ante las adversidades.

- Convocan a reunirse en el Cielo.

- Reconfortan con visiones del Paraíso

- Ahuyentan al demonio.

- Reprenden.

Por otro lado, las ayudas celestiales alcanzan a los siguientes actores:

- Indios devotos (hombres, mujeres y niñas).

- «Falso cristiano» que, finalmente, confiesa correctamente sus pecados.

- Dos caciques (Roque Maracaná y «cacique principal»), figuras representativas para las comunidades de aborígenes. En ambos casos es curioso observar que el socorro celestial les llega aunque no se encontraban reducidos y mantenían las antiguas costumbres poligámicas. Sin embargo, a raíz de la «Divina Palabra» aceptan vivir dentro de una misión siguiendo las pautas de los jesuitas.

- Padres Vaseo y Montoya.

Es importante resaltar que, dentro de la relevancia que le otorgamos a los símbolos, no puede pasar desapercibida la numerología de base tres. En efecto, en reiteradas ocasiones las apariciones (ya sea en imagen o en palabra) se manifiestan repitiendo tres veces su presencia ante los hombres. Ejemplo de ello es la Palabra Divina que ante los indios se deja oír en tres momentos de la noche. También las pinturas de santos, ángeles y de la Virgen expresan empatía con el sufrimiento de padres e indios causados por los ataques paulistas. Dichas imágenes se dejan ver en tres oportunidades y en tres reducciones: San Miguel, Loreto y San Ignacio.

Por otra parte, debemos señalar que en Conquista Espiritual -capítulos XXI a XXVI- el narrador anuncia otra peculiar figura benévola a la que le dedica atención, motivo por el cual nos ha parecido conveniente otorgarle una referencia diferenciada. En medio de la descripción de la entrada a la 
provincia de Tayatí que realizan Montoya y el padre Cristóbal de Mendoza aparece la presencia del Apóstol Santo Tomás. El sujeto del enunciado realiza una minuciosa descripción del pasaje del santo que en el relato se encuentra enmarcada: «Recibiónos esta gente con extraordinarias muestras de amor, (...) Extrañando nosotros tan extraño agasajo, nos dijeron que por tradición tenían, que cuando SantoTomé (pasó por aquellas partes...)...». ${ }^{16}$

Y hacia el final del capítulo XXVI afirma: «Con esto he concluido con la cruz, rastros y señales que hay en el Occidente del glorioso Apóstol; ahora volveré a mis reducciones, deseoso de que alguno tome este rasguño para tratar esta historia con fundamento». ${ }^{17}$

Siguiendo el criterio de coherencia del relato, esta narración está encarada desde la perspectiva de veracidad ya que también pretende reflejar la realidad, el estado de cosas que pertenecen a la circunstancia del religioso. «Euntes in mundum universum praedicate Evangelium omni creaturae» ${ }^{18}$ dice el precepto evangélico del último capítulo de San Marcos. Estas palabras tomadas literalmente generaron la firme creencia de que deberían repetirse en América las experiencias que los discípulos de Cristo habían vivido en Oriente. Varios son los cronistas que mencionan la presencia del Apóstol Santo Tomás ${ }^{19}$ en territorio americano, antecediendo no sólo a la conquista española sino, inclusive, al descubrimiento colombino. Los relatos mencionan que, gracias a las primeras presencias de santos fue posible que se modificaran las creencias indígenas ya que, aceptándolos o rechazándolos, los aborígenes conservaron el recuerdo del pasaje de apóstoles. Para referirnos a este tema debemos mencionar brevemente los ideales utópicos que impregnaron el ambiente europeo del siglo XVI y XVII y que resultaron en una literatura que daba cuenta de descubrimientos geográficos exóticos y que, intrínsecamente, llevaban la idea de hallar espacios «felices» que auguraran nuevos comienzos sociales con abundancia de bienes. Las ideas platónicas que sirvieron de germen a dichos postulados utópicos invadieron los ámbitos religiosos y los escritores abrazaron aquellos conceptos al momento de concretar la evangelización del Nuevo Mundo. A ninguna de las órdenes llegadas al territorio americano les resultó ajeno este pensamiento que significaba la posibilidad de instalar una

16 Antonio Ruiz de Montoya: Conquista Espiritual..., pp. 113-114.

17 Antonio Ruiz de Montoya: Conquista Espiritual..., pp. 128-129.

18 Marcos 16, 15-20.

19 Nos referimos en concreto a «Primer Nueva Corónica y Buen Gobierno» del cronista andino Felipe Guamán Poma de Ayala quien, de manera semejante, emplea el nombre de Bartolomé por Tomás para referirse al pretérito evangelizador de los indígenas. 
nueva sociedad en las tierras recientemente descubiertas para rescatar los ideales de los primigenios tiempos cristianos. Es así que agustinos, jesuitas y dominicos, por citar algunos, produjeron textos en los cuales se hacía mención de creencias indígenas que referían a un pretérito catolicismo. ${ }^{20} \mathrm{El}$ argumento consistía en lo siguiente, así como Santo Tomás:

...había predicado a los gentiles supra Gangem, bien podía interpretarse como más allá de América, puesto que en los siglos XVI y XVII prevalecía la creencia de que Asia y América eran una sola pieza. Al dirigirse hacia el oeste por tierra, a través de las llanuras de América del Norte, se pensaba llegar a la India o a la China. Con bastante rapidez se impuso la idea de que Santo Tomás y San Bartolomé habían evangelizado América, porque las Acta Thomae -reconocidas después como apócrifas- pretendían que Tomás (en realidad un segundo Tomás helenístico) había predicado a los gentiles supra Gangem. (...) Esta convicción se reforzó a medida que los misioneros españoles -pasado el primer entusiasmo del principio- fueron más engañados por los neófitos indios. Se acordaron de que Santo Tomás, al volver del otro lado del Ganges, había dicho a Jesús: "Mitte quo vis, sed non ad Indos. ${ }^{21}$

En nuestra obra será en el capítulo XXIV de Conquista Espiritual que el jesuita presenta un argumento semejante: «...y esta conjetura junta con las tradiciones que quedan referidas, hacen muy probable que Santo Tomé predicó en todo el Occidente, empezando del Brasil (pasando naturalmente en embarcaciones de los romanos, que por la costa de África (como dicen algunos) tenían comunicación con la América, o que Dios por milagro lo llevase, (que se puede tener por más cierto)». ${ }^{22}$

Además, Montoya cita como autoridades los textos fundadores de fray Alonso Ramos Gavilán y de fray Antonio de la Calancha, agustinos ambos, que tempranamente se relacionaron con las creencias religiosas de la zona del Titicaca, Virreinato del Perú.

Montoya da como inicio la mitad del siglo XVI para referir a las noticias de la visita del Apóstol a América y menciona que el testimonio más antiguo corresponde a tripulantes de navíos portugueses. Una segunda referencia

\footnotetext{
${ }^{20}$ Esos relatos, en última instancia, constituyeron búsquedas audaces de hallar en las religiones aborígenes signos precursores del cristianismo.

21 Jacques Lafaye: Mesías, cruzadas, utopías. El judeo-cristianismo en las sociedades ibéricas. Fondo de Cultura Económica, Méjico, 1984, pp. 60-61.

22 Antonio Ruiz de Montoya: Conquista Espiritual..., p. 122.
} 
aparece en la carta de 1538 del Comisario franciscano fray Bernardo de Armentía al Oidor del Consejo de Indias, Juan Bernal Díaz de Lugo. En ella el jesuita refiere una antigua tradición que hablaba del Apóstol Tomás que, predicando en América antes de la conquista de los españoles, trabó relación con un indio llamado Etiguará. Más adelante ${ }^{23}$ cita una carta de 1549 del también jesuita Manuel de Nóbrega ${ }^{24}$ al navarro Martín de Azpilcueta en la que menciona que en Brasil se conservaba el recuerdo de la predicación de Santo Tomás. La lista de personajes que tratan el tema continúa: el P. Lozano en su Historia de la Conquista del Paraguay, Río de la Plata y Tucumán; los jesuitas Francisco de Mendoza y Nicolás del Techo con su Historia provinciae paracuariae; también Simón de Vasconcellos con Chrónica da Companbia de Jesús, do estado do Brasil, entre otros.

A pesar de que varios historiadores reconocen que la tradición del paso de discípulos de Cristo por América podría deberse a la presencia de hechiceros indígenas que, en tiempos precolombinos, recorrían los pueblos aconsejando y profetizando, el recuerdo que guardaban los indios acerca de esos «predicadores» fue interpretado por los religiosos como la presencia de apóstoles cristianos. Y precisamente fueron los jesuitas quienes más se empeñaron en encontrar en los ritos indígenas elementos que pudieran facilitar la asimilación con el cristianismo. De hecho, los misioneros de la Compañía de Jesús basaban la evangelización en el concepto de que la ignorancia invencible de Dios no existe, motivo por el cual la prédica debía desarrollar la idea innata de Dios.

En cuanto al texto de Ruiz de Montoya es importante resaltar que la presencia de Santo Tomás tiene un importante desarrollo cimentado en dos elementos clave tendientes a convalidar la veracidad de la presencia del Apóstol y el carácter anticipatorio de su acción evangelizadora. Dichos aspectos son: la cita de autoridades - entre las cuales se incluye el propio padre Montoya como testigo presencial- y la identificación.

\footnotetext{
23 «...dícelo el P. Pedro de Ribadeneira, de nuestra Compañía, por estas palabras: Y no solamente predicó el santo Apóstol (...), escribe el P. Manuel Nóbrega, Provincial de la Compañía de Jesús que fué en aquella provincia, que los naturales della tienen noticia de Santo Tomé y de haber pasado por aquella tierra, y que muestra algunos rastros y señales dello...». Antonio RuIz de Montoya: Conquista Espiritual..., p. 123.

24 «Un jesuita del Brasil, el padre Nóbrega, ha descrito de manera conmovedora una peregrinación en que él mismo y sus compañeros siguieron, con todo un clan de indios encabezados por el cacique y su mujer, las huellas consideradas milagrosas del apóstol Santo Tomás...». Jacques Lafaye: Mesías, cruzadas, utopías..., p. 60.
} 
La cita de autoridades se presenta bajo tres modalidades: a) las propias palabras del santo; b) las palabras de las autoridades en la materia y c) el testimonio presencial convalidado por las profecías del mismo Santo Tomás.

a) Las palabras del santo: «Esta doctrina que yo ahora os predico, con el tiempo la perderéis; pero cuando después de muchos tiempos vinieren unos sacerdotes sucesores míos, que trajeren cruces como yo traigo, oirán vuestros descendientes esta doctrina». ${ }^{25} \mathrm{Y}$, «Cuando llegare el mar a esta piedra, por divina ordenación vendrán hombres blancos de tierras muy remotas a predicar la doctrina que yo ahora os enseño, y a renovar la memoria della. (...) Esto que yo os predico se os ha de olvidar, (...) volvereis a oir esta misma doctrina que yo os enseño». ${ }^{26}$

b) Las autoridades en la materia: Montoya recurre a las citas de San Ambrosio, del P. Ribadeneyra, del P. Diego Álvarez de Paz, del arzobispo Toribio Alfonso Mogrobejo, del obispo Lorenzo de Grado, del P. Francisco de Alfaro y de fray Alonso Ramos Gavilán. La referencia a esas personalidades está orientada a obtener validez en la argumentación comprobatoria de la existencia del Apóstol en tierras americanas.

c) El propio testimonio presencial convalidado por las profecías de Santo Tomás: «De la misma manera profetizó el Santo la entrada de los de la Compañía en estas partes del Paraguay de que voy tratando, ...»; $; ;^{27}$ «..las huellas que el santo Apóstol dejó impresas en una gran peña que está al fin de la playa, donde desembarcó (...) Yo no las he visto; pero 200 leguas desta costa la tierra adentro, vimos mis compañeros y yo un camino...», ${ }^{28}$ "Yo tengo en mi poder un pedazo desta milagrosa cruz, (...), hallo que de la misma especie, y así lo afirman testigos $(. .$.$) con quien hice la experiencia en el color y olor,...». { }^{29}$

Nos resta decir que el testimonio de Ruiz de Montoya posee también un matiz que lo vincula directamente con su propia tradición cultural andina. Así, tanto como testigo presencial o como receptor de la tradición, el jesuita se incluye en el relato como voz autorizada. La primera prueba que brinda es la marca de las huellas y del báculo del santo en una piedra que como reliquias fueron avaladas por el arzobispo de Lima, Toribio Alfonso Mogrovejo: «En la provincia de los chachapoyas, donde yo estuve, en un pueblo llamado

\footnotetext{
25 Antonio Ruiz de Montoya: Conquista Espiritual..., p. 114.

26 Antonio Ruiz de Montoya: Conquista Espiritual..., p. 123.

27 Antonio Ruiz de Montoya: Conquista Espiritual..., p. 123.

28 Antonio Ruiz de Montoya: Conquista Espiritual..., p. 116.

29 Antonio Ruiz de Montoya: Conquista Espiritual..., p. 126.
} 
San Antonio, a dos leguas deste pueblo está una losa grande de más de un estado de alto y más de seis varas de ancho, (...), que demuestran que allí se arrodillaba el santo, y así lo sienten todos». ${ }^{30}$

En segundo lugar, pero cronológicamente anterior, Montoya vincula la figura de Tomás con la corte de Guáscar Inca. Precisamente es Colla Tupa, quien ordena que sea adorada la piedra que posee las marcas del Apóstol. De esta forma Montoya le otorga la misma validez a la palabra del arzobispo como a la del gobernador del Inca, unidos en el reconocimiento de la presencia del santo: «...porque ya antes que los españoles conquistasen el Perú, Colla Tupa, gobernador de Guarcar Inga, que entró a conquistar aquella provincia, intentó llevarla a la suya, y no pudo; y así dejó mandado que todos los indios la adorasen». ${ }^{31}$

Otro aspecto importante que acerca a nuestro escritor misionero con los rastros que Santo Tomás dejó en el Perú se encuentra en el capítulo XXIII en donde se describe el trayecto del Apóstol por tierras peruanas: desde Cacha, pasando por Cuzco y Collao hasta llegar al adoratorio del Sol (es decir, Copacabana) en el Lago Titicaca. Montoya narra el motivo por el cual Santo Tomás levanta en el pueblo de Carabuco una cruz (signo evidente de su presencia) y las consecuencias que ésto acarrea para los indígenas. El relato sigue con exactitud el pasaje del santo en el Nuevo Mundo de la Historia del célebre santuario de Nuestra Señora de Copacabana de Ramos Gavilán. ${ }^{32}$ En ocasiones Montoya cita al agustino pero en otros momentos, a pesar de ceñirse al texto de Gavilán, no indica la fuente. Esto sucede con el relato de la erupción del volcán de Arequipa, con las marcas que el Apóstol dejó en las cenizas ${ }^{33}$ y con la cruz de Carabuco y sus milagros.

El segundo elemento empleado por Montoya para convalidar la presencia del Santo es la identificación, estrategia persuasiva tendiente a hermanar la figura de Tomás con la de los misioneros jesuitas. Así, las imágenes de Montoya y de Cristóbal de Mendoza en el capítulo XXI replican la primigenia presencia del Apóstol en tres elementos esenciales: el gesto, la situación y el atributo.

30 Antonio Ruiz de Montoya: Conquista Espiritual..., p. 119.

31 Antonio Ruiz de Montoya: Conquista Espiritual..., p. 120.

32 Estos temas aparecen en la crónica de Ramos Gavilán en el cap. 10. Cfr Antonio Ramos Gavilán: Historia del célebre santuario de Nuestra Señora de Copacabana y sus milagros e invención de la Cruz de Carabuco. Segunda edición según impresión príncipe de 1621, Academia boliviana de la Historia, La Paz, 1976, pp. 36-37.

33 «...y con ella dos zapatos como sandalia, de tres suelas, y en la suela por de dentro estampado el sudor del pié, y eran de hombre grande, que causó a todos admiración. Las cuales reliquias se juzgó comunmente eran del santo discípulo del Señon». Antonio Ruız de Montoya: Conquista Espiritual..., p. 118-119. 
Por gesto queremos significar la actitud con que los religiosos enfrentan la tarea evangelizadora, involucrando tanto la acción misionera como el reconocimiento de los indígenas: «Esta tradición les obligó a hacernos tan extraordinario agasajo. Hicimos allí una población muy buena, que fue escala para otras que hicimos en aquella provincia». ${ }^{34}$

En cuanto a situación, ésta constituye el contexto en el que se ubica la identificación del Apóstol con los jesuitas. Misioneros ambos, la labor catequética representa el centro de sus vidas: «Como se iban aumentando los sujetos, íbamos haciendo nuevas entradas a gentiles, y ganando a la iglesia nuevos hijos. Pasó a aquella provincia el V.P. Cristóbal de Mendoza a ayudarnos en aquella cosecha...»; $;^{35}$ «...el P. Francisco Díaz, varón de muchas partes, misionero insigne, (...) se hizo gran maestro de gentiles»; ${ }^{36}$ «...salimos el P. Cristóbal de Mendoza y yo a la provincia de Tayatí, tierra muy áspera y montuosa, habitada por gentiles». ${ }^{37}$

Respecto del atributo hemos hallado que en sus dos manifestaciones (palabra y signo) es donde aparecen matices más ricos respecto de la semejanza entre las figuras del Santo y la de los jesuitas. Así, el atributo centrado en la palabra evangelizadora se presenta lógicamente como estrategia de conversión. La palabra será reconocida como la herencia del Apóstol y como instrumento de transmisión de la idea pretérita que guardaban los indios sobre la Trinidad.

De cuya enseñanza y doctrina les quedó hasta nuestros tiempos el conocimiento del abscóndido Misterio de la santísima Trinidad, si bien ya olvidados celebran supersticiosamente una célebre festividad deste misterio en el Perú. Halláronse tres estatuas del sol, que llamaban Apointi, Churinti, Intiqua o Qui, que quiere decir el Padre y Señor Sol, el hijo del Sol, el hermano del Sol. Y que el Santo les explicó la unidad destas tres Personas divinas, da cuenta un ídolo que llamaron Tangatanga, en que adoraban a este uno tres, y en tres uno,lo cual tengo por muy probable que les quedó del Apóstol, y ellos lo aplicaron a sus ídolos. ${ }^{38}$

\footnotetext{
34 Antonio Ruiz de Montoya: Conquista Espiritual..., p. 114.

35 Antonio Ruiz de Montoya: Conquista Espiritual..., p. 113.

36 Antonio Ruiz de Montoya: Conquista Espiritual..., p. 113.

37 Antonio Ruiz de Montoya: Conquista Espiritual..., p. 113.

38 Antonio Ruiz de Montoya: Conquista Espiritual..., p. 123.
} 
Rápidamente, Montoya aclara que el conocimiento del abscóndito Misterio de la Santísima Trinidad se fue olvidando y desvirtuando con el paso del tiempo hasta llegar a una imagen de un ídolo pagano.

Recibiónos esta gente con extraordinarias muestras de amor, danzas y regocijos, cosa que hasta allí no habíamos experimentado. (...) Extrañando nosotros tan extraño agasajo, nos dijeron que por tradición muy antigua y recibida de sus antepasados tenían, que cuando Santo Tomé pasó por aquellas partes, les dijo estas palabras: 'Esta doctrina que yo ahora os predico, con el tiempo la perderéis; pero cuando después de muchos tiempos vinieren unos sacerdotes sucesores míos, que trajeren cruces como yo traigo, oirán vuestros descendientes esta doctrina. ${ }^{39}$

Por otro lado, la palabra cobra especial importancia en el discurso de Montoya al brindar precisiones lingüísticas sobre el nombre del Apóstol y de la Trinidad, reafirmando, así, en un acto de enunciación, su antigua existencia: «..., nos dijeron que por tradición muy antigua y recibida de sus antepasados tenían, que cuando Santo Tomé (a quien comunmente en la provincia del Paraguay llaman Pay Zumé, y en las del Perú Pay Tumé) pasó por aquellas partes» $;^{40}$ «De manera que ya queda conocido por Tomé en el Brasil, Paraguay y Perú...». ${ }^{41}$

...y empezando por el nombre que dan a los sacerdotes, (...) Llámanlos Abaré, que quiere decir Homo segregatus a venere. (...) Este nombre a ninguno de los indios convino desde sus progenitores hasta Santo Tomé, sino al mismo Santo, de quien comunmente dicen los indios que fué Pay Abaré, Padre sacerdote, y en propios términos Padre, (...) Toda esta fuerza tiene esta breve palabra; (...) Y aunque el vocablo Pay, que quiere decir Padre, lo usurparon los viejos, los magos y los hechiceros, honráronse con él, jamás el de Abaré lo han admitido... ${ }^{42}$

...el conocimiento del abscóndito Misterio de la santísima Trinidad (...) Halláronse tres estatuas del sol, que llamaban Apointi, Churinti, Intiqua o Qui, que quiere decir el Padre y Señor Sol (...) Y que el Santo les explicó la unidad destas tres Personas divinas, (...) lo cual tengo por muy probable que les quedó del Apóstol (...). Y así entiendo, que el nombre que en el

\footnotetext{
39 Antonio Ruiz de Montoya: Conquista Espiritual..., pp. 113-114.

40 Antonio Ruiz de Montoya: Conquista Espiritual..., pp. 113-114.

41 Antonio Ruiz de Montoya: Conquista Espiritual..., pp. 123.

42 Antonio Ruiz de Montoya: Conquista Espiritual..., p. 114.
} 
Paraguay le dan a Dios que es Tupá (...) oyendo las maravillas que de Dios les anunciaba el Santo... ${ }^{43}$

El atributo se completa en la portación de la vara-cruz cuya finalidad principal es ser el signo distintivo para el lograr el reconocimiento: «...usamos siempre llevar en las manos unas cruces de dos varas de alto y de un dedo de grueso, para que por esta insignia se mostrase nuestra predicación»; ${ }^{44} \ll \ldots$ la predicación del Evangelio, que es imposible hacerse sin cruz...». ${ }^{45}$

De manera que se saca de lo dicho por muy probable la tradición que en el Paraguay se tiene, de haber dicho el santo Apóstol, que cuando viniesen unos sucesores suyos que trajesen cruces como él traía, volverían a oír la doctrina que él les enseñaba. (...) Esto que yo os predico se os ha de olvidar, pero cuando vengan unos sacerdotes míos, que traigan cruces, como yo traigo, entonces volveréis a oír esta misma doctrina que yo os enseño. ${ }^{46}$

Para concluir diremos que la figura de Santo Tomás en el relato de la evangelización constituye una presencia anticipatoria de la tarea que tiempo después emprenderán los padres jesuitas. Y si bien las misiones son el ámbito propicio para la interacción del hombre con la divinidad, es en el proyecto de su construcción que la aparición pretérita del Apóstol se conforma en un claro mensaje esperanzador. La renovada presencia de la palabra del discípulo de Cristo en los padres augura la conformación de un espacio en el que los indios llevarán una vida apegada al precepto y la doctrina, es decir, una vida que -para los cánones de la época- podría decirse ordenada.

\section{Conclusiones}

Hemos abordado el estudio de las figuras benéficas que aparecen en Conquista Espiritual siguiendo dos líneas: una primera dedicada a priorizar

\footnotetext{
43 Antonio Ruiz de Montoya: Conquista Espiritual..., pp. 123-124.

44 Antonio Ruiz de Montoya: Conquista Espiritual..., p. 113.

45 Antonio Ruiz de Montoya: Conquista Espiritual..., p. 127.

46 Antonio Ruiz de Montoya: Conquista Espiritual..., p. 123.
} 
la estructura discursiva con el fin de resaltar las estrategias del enunciado. $\mathrm{Al}$ respecto observamos que aquel mantiene la coherencia que le otorga univocidad al texto. El enfoque lingüístico aplicado al corpus seleccionado de la obra nos permitió identificar el tema o concepto general para luego centrarnos en las oraciones a fin de comprobar que permanecen en el mismo universo de significado. Con estos elementos podemos afirmar que todo el texto ha sido construido sobre la base de enunciados apropiados y oportunos tendientes a describir la realidad. En otras palabras, Conquista Espiritual como informe que describe las circunstancias de la evangelización en tierras de la Provincia Jesuítica del Paraguay refleja el trabajo de Montoya (sostenido exclusivamente por la fe) en dos ámbitos: el espiritual y el terrenal. Este relato transmite un mundo, un estado de cosas en el que los seres sobrenaturales (de signo positivo, en esta ocasión) se presentan cotidianamente como ayudantes de los padres y de los indios.

La segunda línea de abordaje se ha centrado en la dimensión simbólica del texto, a partir de la cual observamos que toda la narración -tensionada hacia la finalidad salvífica del hombre- descubre lo Sagrado en el espacio de las misiones y en la acción de los jesuitas. En estos ámbitos se inserta el concepto del libre albedrío como base de la tarea evangelizadora y es a través de éste que Montoya construye un discurso tendiente a generar una acción perlocutiva cuya finalidad última consiste en ganar voluntades. Dentro del universo cultural que aparece en Conquista Espiritual resulta previsible que se dé el encuentro entre figuras celestiales y los hombres.

Así, las imágenes benévolas (bajo la forma de «rescate») representan símbolos salvíficos ya que, a pesar de la existencia del mal, siempre está la posibilidad de que ocurra el bien. Y por ello podemos definir a Antonio Ruiz de Montoya como un «intellectus spei» ya que, a través de un discurso basado en la idea de la salvación, construye en Conquista Espiritual un texto que redunda en una imagen cultural de dimensión simbólica. Será a partir de las figuras benéficas (en cuanto manifestaciones de lo Sagrado) que se revelará la condición de «gracia» (propia de todos los hombres -padres e indios-) y que posibilitará la salvación.

También, a través del estudio lingüístico hemos podido aislar las proposiciones empleando la generalización y abstracción (macrorreglas) que todo lector u oyente realiza a fin de comprender y sintetizar la información recibida. Y hemos observado que todas las proposiciones referidas a las figuras benévolas pertenecen al ámbito de la descripción de las circunstancias. Así, la labor 
evangelizadora tendiente a lograr la salvación de los guaraníes constituye el centro del texto de Montoya (acto aseverativo). Las presencias celestiales reafirman el vínculo hombre-Dios mediatizado por la labor y la prédica de los jesuitas. Este estado de cosas transparenta el universo del jesuita basado en la creencia y el conocimiento. Y es por eso que el sujeto del enunciado apela a las figuras de «rescate» como único medio posible para liberar a los indios del mal.

\section{Anexo}

\section{Cuadro I}

\begin{tabular}{|c|c|}
\hline Proposición 1 (p.91; cap. XIV) & «mostrarse para alentar» \\
\hline Proposición 2 (p.93; cap. XV) & «escuchar amonesta-ción para radicarse en Loreto» \\
\hline Proposición 3 (p.95; cap. XV) & «hablar/ordenar» \\
\hline Proposición 4 (p.95; cap.XV ) & «herir en el costado/hablar» \\
\hline Proposición 5 (p.98; cap.XVII ) & «socorrer» \\
\hline Proposición 6 (p.98; cap. XVII) & «dar testimonio/conducir a la ciudad de Dios» \\
\hline Proposición 7 (p.102; cap.XVIII ) & «mostrarse» \\
\hline Proposición 8 (p.103; cap.XVIII) & «invitar al Cielo» \\
\hline Proposición 9 (p.104; cap.XVIII) & «conducir para visitar al Santísimo Sacramento» \\
\hline Proposición 10 (p.105; cap.XVIII) & «sentir contacto» \\
\hline Proposición 11(p.141, cap.XXXI) & «hacerse oír y ver» \\
\hline Proposición 12 (p.162; cap.XXXVIII) & «sudar» \\
\hline Proposición 13 (p.162; cap.XXXVIII) & «llorar» \\
\hline Proposición 14 (p.180; cap.XL) & «dar nuevas de «nuestra Madre»» \\
\hline Proposición 15 (p.205; cap.XLVII ) & «relevar culpa» \\
\hline Proposición 16 (p. 205; cap.XLVII) & «reprender» \\
\hline Proposición 17 (p.206; cap.XLVII) & «advertir» \\
\hline Proposición 18 (p.211; cap.L) & «incitar a confesión y comunión» \\
\hline Proposición 19 (p.220; cap.LIV) & «ahuyentar demonio y socorrer» \\
\hline Proposición 20 (p.233; cap. LIX) & «mostrarse y llevarse a niña de cinco años» \\
\hline Proposición 21 (p.233; cap.LIX) & «mostrarse en la iglesia» \\
\hline Proposición 22 (p.241; cap.LXIV) & «sudar para mostrar consuelo» \\
\hline Proposición 23 (p.241; cap.LXIV) & «sudar para mostrar consuelo» \\
\hline Proposición 24 (p.265; cap.LXIV) & «sudar para mostrar consuelo» \\
\hline Proposición 25 (p.265; cap.LXXIV) & «llorar para mostrar dolor» \\
\hline Proposición 26 (p.266; cap.LXXIV) & «sudar para demostrar sentimiento» \\
\hline Proposición 27 (p.266 cap.LXXIV) & «sudar para demostrar sentimiento» \\
\hline
\end{tabular}




\section{Cuadro II}

\begin{tabular}{|c|c|c|}
\hline \multirow{4}{*}{ АСTO 1 p.91 cap. XIV } & acción & mostrarse para alentar \\
\hline & agente & padre Urtazum difunto \\
\hline & objeto & amigo devoto religioso \\
\hline & circunstancia & «una noche» \\
\hline \multirow{4}{*}{ АСТО 2 p.93 cap. XV } & acción & escuchar amonestación para radicarse en Loreto \\
\hline & agente & Dios \\
\hline & objeto & cacique Roque \\
\hline & circunstancia & «esta noche» \\
\hline \multirow{4}{*}{ АСТО 3 p.95 cap. XV } & acción & hablar / ordenar \\
\hline & agente & Palabra Divina \\
\hline & objeto & Padre \\
\hline & circunstancia & pasado al amanecer «después de medianoche» \\
\hline \multirow{4}{*}{ АСТО 4 p.95 cap. XV } & acción & herir en el costado/hablar \\
\hline & agente & Divina Palabra \\
\hline & objeto & cacique principal \\
\hline & circunstancia & «anoche» \\
\hline \multirow{4}{*}{ АСТО 5 p.98 cap. XVII } & acción & Socorrer \\
\hline & agente & San Pedro, Ángel de la Guarda, Arcángel Miguel \\
\hline & objeto & buen indio \\
\hline & circunstancia & estando muerto \\
\hline \multirow{4}{*}{ АСТО 6 p.98 cap. XVII } & acción & dar testimonio/conducir a la ciudad de Dios \\
\hline & agente & buen indio difunto y resucitado \\
\hline & objeto & parientes para que crean la prédica de los padres \\
\hline & circunstancia & $\mathrm{X}$ \\
\hline \multirow{4}{*}{ АСTO 7 p.102 cap. XVIII } & acción & mostrarse \\
\hline & agente & tres figuras \\
\hline & objeto & indios devotos de Loreto \\
\hline & circunstancia & «en la noche a la claridad de la luna» \\
\hline \multirow{4}{*}{ АСTO 8 p.103 cap. XVIII } & acción & invitar al Cielo \\
\hline & agente & indio cantante discípulo difunto \\
\hline & objeto & padre Vaseo \\
\hline & circunstancia & «tocaron a la ventana» \\
\hline \multirow{4}{*}{ ACTO 9 p.104 cap. XVIII } & acción & conducir para visitar al Santísimo Sacramento \\
\hline & agente & Ángel de la Guarda \\
\hline & objeto & indio hábil y diestro en la música \\
\hline & circunstancia & «La víspera de su muerte» \\
\hline \multirow{4}{*}{ АСTO 10 p.105 cap. XVIII } & acción & sentir contacto \\
\hline & agente & Almas del Purgatorio \\
\hline & objeto & padre \\
\hline & circunstancia & «de noche orando» \\
\hline
\end{tabular}




\begin{tabular}{|c|c|c|}
\hline \multirow{4}{*}{ АСТО 11 p.141 cap. XXXI } & acción & hacerse oír y ver \\
\hline & agente & alma del Purgatorio \\
\hline & objeto & padre Montoya e indios cristianos \\
\hline & circunstancia & «a las nueve de la noche en lo más oscuro della» \\
\hline \multirow{4}{*}{$\begin{array}{l}\text { ACTO } 12 \text { p.162 cap. } \\
\text { XXXVIII }\end{array}$} & acción & sudar \\
\hline & agente & imagen pintada de la Virgen \\
\hline & objeto & padre e indios cristianos (acompañados por el Cielo) \\
\hline & circunstancia & mudanza de reducciones Loreto y San Ignacio \\
\hline \multirow{4}{*}{$\begin{array}{l}\text { ACTO } 13 \text { p.162 cap. } \\
\text { XXXVIII }\end{array}$} & acción & Ilorar \\
\hline & agente & imagen pintada de ángeles \\
\hline & objeto & padres e indios cristianos (acompañados por el Cielo) \\
\hline & circunstancia & mudanza de reducciones Loreto y San Ignacio \\
\hline \multirow{4}{*}{ АСТО 14 p.180 cap. XL } & acción & dar nuevas de «nuestra Madre» \\
\hline & agente & Isabel, india devota difunta \\
\hline & objeto & indios de la Congregación de la Virgen \\
\hline & circunstancia & «Llegó la medianoche» \\
\hline \multirow{4}{*}{ ACTO 15 p.205 cap. XLVII } & acción & relevar culpa \\
\hline & agente & San Ignacio \\
\hline & objeto & indio cristiano \\
\hline & circunstancia & «Estando a medianoche» \\
\hline \multirow{4}{*}{ АCTO 16 p.205 cap.XLVII } & acción & reprender \\
\hline & agente & San Ignacio \\
\hline & objeto & india cristiana \\
\hline & circunstancia & $\mathrm{X}$ \\
\hline \multirow{4}{*}{ ACTO 17 p.206 cap. XLVII } & acción & advertir \\
\hline & agente & Virgen \\
\hline & objeto & india cristiana \\
\hline & circunstancia & «una noche ... se quedó dormida» \\
\hline \multirow{4}{*}{ ACTO 18 p.211 cap. L } & acción & incitar a confesión y comunión \\
\hline & agente & San Francisco Javier \\
\hline & objeto & indio falso cristiano \\
\hline & circunstancia & $\mathrm{X}$ \\
\hline \multirow{4}{*}{ ACTO 19 p.220 cap. LIV } & acción & ahuyentar demonio y socorrer \\
\hline & agente & Virgen \\
\hline & objeto & indio mozo \\
\hline & circunstancia & «una noche» \\
\hline \multirow{4}{*}{ АСTO 20 p.233 cap. LIX } & acción & mostrarse y llevarse a niña de cinco años \\
\hline & agente & Virgen \\
\hline & objeto & niñas cristianas de cinco y tres años \\
\hline & circunstancia & «juntas a la puerta de su casa» \\
\hline
\end{tabular}




\begin{tabular}{|c|c|c|}
\hline \multirow{4}{*}{ АСТО 21 p.233 cap. LIX } & acción & mostrarse en la iglesia \\
\hline & agente & Virgen \\
\hline & objeto & niña cristiana de cinco años \\
\hline & circunstancia & «En amaneciendo» \\
\hline \multirow{4}{*}{ ACTO 22 p.241 cap. LXIV } & acción & sudar para mostrar consuelo \\
\hline & agente & imagen de Cristo \\
\hline & objeto & indios cristianos y padre Miguel Gómez \\
\hline & circunstancia & «reducción de San Miguel» \\
\hline \multirow{4}{*}{ АСТО 23 p.241 cap. LXIV } & acción & sudar para mostrar consuelo \\
\hline & agente & imagen de Ntra. Sra. de la Asunción y de S. Ignacio \\
\hline & objeto & indios cristianos y padres \\
\hline & circunstancia & «en villa de Espíritu Santo» \\
\hline \multirow{4}{*}{ АСTO 24 p.265 cap. LXIV } & acción & sudar para mostrar consuelo \\
\hline & agente & imagen de Virgen \\
\hline & objeto & indios cristianos y padres \\
\hline & circunstancia & «En Guaira» \\
\hline \multirow{4}{*}{ АСTO 25 p.265 cap. LXXIV } & acción & Ilorar para mostrar dolor \\
\hline & agente & dos ángeles \\
\hline & objeto & indios cristianos y padres \\
\hline & circunstancia & «En Santo Ángel» \\
\hline \multirow{4}{*}{ АСTO 26 p.266 cap. LXXIV } & acción & sudar para demostrar sentimiento \\
\hline & agente & imagen de S. Ignacio y de S. Francisco Javier \\
\hline & objeto & indios cristianos y padres \\
\hline & circunstancia & «en una reducción desta» \\
\hline \multirow{4}{*}{ АСТО 27 p.266 cap. LXXIV } & acción & sudar para demostrar sentimiento \\
\hline & agente & imagen de Virgen \\
\hline & objeto & indios cristianos y padres \\
\hline & circunstancia & «en su misma tierra» \\
\hline
\end{tabular}




\section{Bibliografía General:}

Armani, Antonio: Ciudad de Dios y ciudad del sol. «Estado» jesuita de los guaranies (1609-1768). Traducción de Marcos Lara, Fondo de Cultura Económica, Méjico, 1988.

Calvi, Edgardo: Las milicias de las doctrinas jesuiticas del Paraguay. Origen, evolución e influencia social y política. En: JORNADAS. Aporte de las Universidades Católicas al Quinto Centenario del descubrimiento y de la evangelización de América. Su misión ante la nueva evangelización. Tomo II. Buenos Aires, septiembre, 1992, pp. 113-123

LafaYe, Jacques: Mesías, cruzadas, utopías. El judeo-cristianismo en las sociedades ibéricas. Traducción de Juan José Utrilla, Fondo de Cultura Económica, Méjico, 1984.

LÉvi-Strauss, Claude: Antropología estructural. Mito, sociedad, humanidades. Traducción de Juan Almela, Siglo XXI, Méjico, 1997.

Ramos Gavilán, Alonso: Historia del célebre santuario de Nuestra Señora de Copacabana y sus milagros e invención de la Cruz de Carabuco. Segunda edición según impresión príncipe de 1621, Academia boliviana de la Historia, La Paz, 1976.

Ricoeur, Paul: Hermenéutica y Estructuralismo. Traducción de Graziella Barravalle y María Teresa La Valle. Megápolis, Buenos Aires, 1975.

Van Dijk, Teun: La ciencia del texto. Traducción de Sibila Hunzinger. Paidós, Barcelona, 1992. 